\title{
ECONOMIA COLABORATIVA E CONSUMO COMPARTILHADO: CORPORAÇÕES E PLATAFORMAS DIGITAIS MOLDANDO UMA NOVA ECONOMIA EM UM MUNDO CONECTADO EM REDES.
}

\author{
Marcos Medeiros de Souza
}

Universidade do Oeste Paulista - UNOESTE, Presidente Prudente, SP. E-mail: $\underline{\text { msouza@unoeste.br }}$

\begin{abstract}
RESUMO
Atualmente os termos economia colaborativa e consumo compartilhado têm sido utilizados para denominar a etapa atual de uma evolução da economia e da sociedade que está apontando para novas formas de se fazer negócios e é delineada em parte pelas tecnologias digitais. Uma sociedade global e coletiva, organizada economicamente em plataformas digitais, está surgindo no mundo online. Condutas associativas, teorias sociais e economia convergindo para dar contorno a novos modelos de mercados e de consumo. O objetivo geral desse artigo é investigar como a digitalização da sociedade está dando forma a uma nova economia, e em termos específicos, (a) o surgimento do consumo colaborativo, (b) a convergência entre redes sociais, informatização das empresas e economia, (c) características e modelos de negócios e (d) as novas corporações digitais. Trata-se de uma pesquisa exploratória que utilizou a pesquisa bibliográfica para coletar dados e delinear um quadro teórico sobre o tema. A investigação mostrou que há uma mudança cultural nos hábitos de consumo em um momento que ocorre uma excepcional confluência entre tecnologias digitais e desenvolvimento cultural que torna possível o surgimento de uma nova economia colaborativa organizada em redes de consumo compartilhado. Compartilhamento sempre dependeu de uma rede, e atualmente nós temos uma que está redefinindo seu propósito, significado e possibilidades: a Internet. De muitas maneiras, pode-se ver o surgimento da Economia Compartilhada como o ápice de um processo natural da tendência rumo à "corporação digital", à terceirização e à inovação aberta e a permeabilidade dos limites das empresas.
\end{abstract}

Palavras-chave: economia colaborativa; economia de compartilhamento; consumo compartilhado; plataformas digitais; corporações digitais.

\section{COLLABORATIVE ECONOMY AND SHARED CONSUMPTION: CORPORATIONS AND DIGITAL PLATFORMS SHAPING A NEW ECONOMY IN A NETWORK CONNECTED WORLD}

\begin{abstract}
Today the terms collaborative economy and shared consumption are been used to name the current stage of an evolution of the economy and society that is pointing to new ways of doing business and is outlined in part by digital technologies. A global and collective society, organized economically on digital platforms is emerging in the online world. Associative behaviors, social theories and economy are converging to give shape to new models of business markets and consumption. The general aim of this article is to investigate how the digitalization of society is shaping a new economy, and the specific goals, (a) the emergence of collaborative consumption, (b) convergence between social networks and shared consumption, c) collaborative networks and business models and d) the new digital corporations. It is an exploratory research that used bibliographical research to collect data and to delineate a theoretical framework on the subject. Research has shown that there is a cultural shift in consumer habits at a time when there is an exceptional confluence between digital technologies and cultural development that makes possible the emergence of a new collaborative economy organized in networks of shared consumption. Sharing has always being supported by networks, and actually we have a huge one that is redefining its possibilities: the Internet. In many ways, we can see the emergence of Shared Economy as the apex of a natural trend toward digital corporation, outsourcing and open innovation, and the permeability of corporate boundaries.
\end{abstract}

Keywords: collaborative economy; sharing economy; shared consumption; digital platforms; digital corporations. 


\section{INTRODUÇÃO}

Uma mudança radical nas maneiras de se organizar a atividade econômica está a caminho e deve se tornar cada vez mais dominante nesse século. Uma variedade de comportamentos (e organizações) que muitos chamam, de forma otimista, de "economia de compartilhamento", são nuances precoces de um futuro no qual as trocas entre pares se tornará cada vez mais o modo habitual e as comunidades, no seu todo, tomarão o lugar das corporações no centro do capitalismo (SUNDARARAJAN, 2016). Esse autor cunha o termo "economia de compartilhamento" para designar a fase atual de uma evolução da economia e da sociedade que está ocorrendo e é formatada em parte pelas tecnologias digitais de informação e comunicação (TIC's). Uma sociedade global e coletiva está surgindo no mundo online. Comportamentos associativos, teorias sociais e economia andando juntos para formar novos modelos de negócios.

Ao examinarmos os artigos recentes, tudo parece indicar que colaboração e compartilhamento estão acontecendo em formas e escalas nunca vistas antes. Todos os dias pessoas utilizam o "consumo colaborativo" - que é o compartilhamento, empréstimo, troca e locação de bens e de serviços, redesenhadas através do uso das tecnologias digitais e das comunidades organizadas em redes sociais.

$\mathrm{O}$ modo de se fazer trocas, comércio e empregos associados à economia de compartilhamento não são novas. As tecnologias digitais parecem nos estar levando de volta para comportamentos familiares e comunitários de compartilhamento, de empreendedorismo e outras formas de trocas comunitárias que existiam no passado. Um breve olhar sobre a evolução da atividade econômica ao longo do tempo sugere que antes da revolução industrial uma porcentagem significativa das trocas econômicas era feita entre pares, de forma comunitária e costuradas de várias maneiras por relações sociais. A confiança necessária para se fazer comércio era possível primeiramente através de laços sociais de diferentes tipos. Portanto, fica intrínseca a questão: existe uma nova economia? O objetivo desse artigo é responder essa questão em termos amplos e gerais, e de modo específico, revelar seu surgimento, suas características, modelos de negócios e a nova onda das corporações digitais.

\section{MÉTODOS}

Foi realizada uma pesquisa bibliográfica sobre autores e artigos recentes sobre a problemática apresentada buscando trazer contribuições ao quadro teórico que está se delineando no horizonte acadêmico sobre o que se está sendo denominado de nova economia. Trata-se de uma pesquisa exploratória de cunho qualitativo evidenciando a ligação entre termos relativos à nova economia tais como economia colaborativa, economia de compartilhamento, consumo compartilhado, redes sociais e plataformas digitais para investigar se há, de fato, o surgimento de uma nova economia.

\section{RESULTADOS}

Estas maneiras inovadoras de se fazer coisas familiares e comunitárias estão sendo potencializadas por tecnologias digitais que expandem as comunidades econômicas muito além dos amigos e familiares que vivem em nossa vizinhança, alcançando um mundo global e conectado. Isso permite um ganho de escala fenomenal. Possivelmente o maior impacto das tecnologias digitais sobre os negócios e a sociedade (SUNDARARAJAN, 2016, p. 4-5).

É o consumo colaborativo capacitando as pessoas a terem acesso a produtos e serviços sem a necessidade de se tornarem proprietários e, respectivamente, economizarem dinheiro, espaço, tempo, fazerem novos amigos e se tornarem cidadãos do mundo, criando uma cultura do "o que é meu, é seu" (BOTSMAN; ROGERS, 2010, xv).

A convergência de redes sociais, uma renovada crença na importância das comunidades, preocupações ambientais e consciência dos custos sociais envolvidos estão movendo a sociedade para longe das formas centralizadas e massivas de consumo e nos aproximando a formas agregadas e abertas de cooperação (BOTSMAN; ROGERS, 2010, xx).

Consumo Colaborativo é baseado em tecnologias digitais ( $\mathrm{TIC}^{\prime} \mathrm{s}$ ) e atitudes em redes sociais. Estas interações por meios virtuais têm nos ajudado a experimentar a ideia que cooperação não precisa vir à custa de nossa individualidade, e sim abrindo as portas para um comportamento natural e interessante de compartilhar coisas.

Por meio das redes, os indivíduos, mesmo desconhecidos, se conectam, realizam trocas, compartilham informações e cooperam, impulsionando a rápida disseminação das 
plataformas de economia compartilhada (SCHOR, 2014).

De fato, nós acreditamos que pessoas irão olhar para trás e reconhecer que consumo colaborativo começou online - postando comentários, compartilhando arquivos, códigos de programação, fotos, vídeos e conhecimento. $\mathrm{E}$ agora, nós alcançamos um ponto de inflexão onde estamos a aplicar os mesmos princípios colaborativos e comportamentos de compartilhamento para outras áreas do mundo físico de nossas vidas cotidianas (BOTSMAN; ROGERS, 2010, xx).

Quadro 1. Evolução do Consumo Colaborativo online

\section{Período Descrição}

1991 - 2000 No contexto norte-americano, as chamadas "vendas de garagem" ou "garage sales" (venda de produtos usados realizado nas garagens das casas dos indivíduos que queriam vender bens sem uso e obter uma renda extra) emergiram no espaço virtual com o surgimento da Internet. Empresas pioneiras como Clothing Swap (troca de roupas) e Make Up Alley (venda de cosméticos) desenvolveram plataformas digitais de troca e venda de produtos usados que atingiu uma grande população. Na sequência, surgiram empresas como Ebay que funcionam como um tipo de "classificados" online. Em 1997, Netflix e Zipcar emergiram como um modelo alternativo de locação de filmes e carros, contribuindo para o crescimento do setor de serviços. Em 1998, foi criado o gigante Google e em 2000, a bolha das empresas "ponto.com" explodiu e diversas empresas foram à falência. Esse evento fez com que as pessoas parassem de confiar nos especialistas da Internet e passaram a confiar mais nas informações e avaliações provenientes de suas comunidades e amigos.

2001 - 2005 Diversos sites para compartilhamento de informações e avaliações sobre produtos e serviços feitas por usuários começaram a surgir. Em 2001, o Wikipédia iniciou suas atividades. Em 2004 foi lançado o Facebook nos EUA, transformando radicalmente o modo de interação online entre seus membros. A compra de produtos via Internet ganha contornos expressivos em diversas partes do mundo.

2006 - 2008 O rápido avanço da comunicação via Internet proporcionou uma revolução nos serviços de locação e, entre outras mudanças, iniciou a democratização do acesso ao luxo por intermédio de empresas como Bag Borrow or Steal (locação de bolsas e acessórios de luxo), Swap Style (locação de roupas de estilistas famosos), Homeaway (locação e troca de casas e propriedades privadas) e Sherpa Report (locação e compartilhamento de barcos, aviões e propriedades de luxo). O Facebook foi descoberto pelas empresas que passaram a interagir online com públicos de seu interesse.

2009 - 2010 Nesse período, sites e serviços de consumo colaborativo tornaram-se mais sociais, com a integração dessas plataformas com as redes sociais como Facebook.

Fonte: Botsman e Rogers (2010), traduzido e adaptado pelo autor.

Tudo é uma questão de comportamento social com reflexos sobre os modelos de negócios e a atividade econômica em si. O movimento vem das pessoas e molda a sociedade e se torna um modo de vida que atinge a atividade econômica, por meio das trocas, do comércio e dos serviços prestados. Quem sabe, uma mudança nos conceitos de compartilhamento e colaboração seja necessária para o mundo dos negócios. Pois afeta questões capitais envolvendo propriedade e consumo, alocação e distribuição de recursos naturais, materiais e financeiros.

\section{O Surgimento da Economia Colaborativa e Consumo Compartilhado}

Adam Smith e Milton Friedman acreditavam que um indivíduo em busca de seu próprio interesse promoveria o bem para a sociedade como um todo. Em poucas gerações este conceito foi transformado a partir de uma narrativa vigorosa e ingênua em uma busca frenética por uma identidade pessoal através do consumo de marcas, produtos e serviços e se tornar um sistema extremo de insatisfação consumista. Nós acabamos por acreditar que era melhor se amparar em grandes corporações e empresas do que cooperar com nossos pares. Coletividade e valores comunitários foram 
banidos em favor do consumo independente e o imaginário popular centrado no individualismo (BOTSMAN E ROGERS, 2010, p. 42).

A sociedade pode estar saindo desse êxtase consumista em que vivemos nas últimas cinco décadas ou mais. No centro dessa transformação há dois fenômenos interligados. $\mathrm{O}$ primeiro é mudança de valores. Há uma crescente consciência sobre consumo, que desenvolvimento e consumismo não podem ser embasados em recursos infinitos. Afinal, sabemos que não é sustentável, do ponto de vista dos recursos naturais disponíveis em nosso planeta, atender a toda sua população em um modo de vida consumista. Consequentemente, nós estamos buscando meios para se obter mais daquilo que se compra, procurando saber que impactos o modo de produção afeta questões ambientais e de sustentabilidade, visando consumir aquilo que faz bem para a sociedade no longo prazo.

A necessidade de estimular valores, significados e senso de comunidade em nossas vidas está emergindo em todos os lugares. 0 desejo de encontrar propósito e estórias autênticas por trás daquilo que compramos, fazemos e criamos. Mudanças de valores já ocorreram antes, como mostram os movimentos ativistas dos anos 1960 e 1970. Para que novos hábitos, ideias e visões de mundo se tornem permanentes, eles precisam de uma rede e uma plataforma que transformem princípios em atitudes e comportamentos em uma escala global (SUNDARARAJAN, 2016).

As mudanças que estamos discutindo nesse artigo estão ocorrendo em um tempo que ocorre uma extraordinária confluência entre tecnologias digitais e desenvolvimento cultural que torna a realização desses valores não somente possível, mas duradoura. Compartilhamento sempre dependeu de uma rede, e atualmente nós temos uma que está redefinindo seu propósito, significado e possibilidades: a Internet.

O fluxo de capital para esses novos modelos de negócios parece indicar uma nova bolha financeira. Mas por trás de toda excitação há uma ideia interessante: há um estoque de recursos ociosos na economia. Ativos permanecem ociosos - o carro comum é dirigido apenas uma hora por dia - e trabalhadores tem tempo e habilidades sem uso. Se você pode conectar pessoas que estão dispostas a pagar para alugá-los, você reduz o desperdício e acaba por ter um sistema mais eficiente (SUROWECKI, 2013).

Botsman e Rogers (2010) sustentam que o século 20 foi definido pelo "hiper-consumo", e o século 21 se prontifica para se tornar o século do "consumo colaborativo". As diferenças se situam no modo de acesso e escolha dos produtos e serviços disponibilizados na economia, como mostrado no Quadro 2.

Quadro 2. Modelos de consumo e suas características

\begin{tabular}{lll}
\multicolumn{2}{c}{ Hiper-consumo (século 20) } & Consumo Colaborativo (século 21) \\
\hline$\checkmark$ Crédito & $\checkmark$ & Reputação \\
$\checkmark$ & Propaganda & $\checkmark$ Comunidade \\
$\checkmark$ Propriedade & $\checkmark$ Compartilhamento \\
\hline
\end{tabular}

Fonte: adaptado de Botsman; Rogers, 2010.

A colaboração que está no coração do Consumo Colaborativo pode ser local e face-aface, ou pode usar a Internet para conectar, para combinar, formar grupos e encontrar algo ou alguém para criar interações entre pares e pessoas. De forma simples, pessoas estão compartilhando novamente com suas comunidades ou coletivos - seja em um escritório, na vizinhança, em um prédio residencial, em uma escola ou em um grupo no Facebook. (BOTSMAN; ROGERS, 2010, xv).
De forma geral, toda rede se apoia em suas conexões, e se sustenta em toda extensão. O mesmo ocorre com as redes sociais conectadas por tecnologias digitais, que enraizada em valores culturais, possibilitam a emergência da nova Economia Colaborativa. Para estabelecermos alguns parâmetros, vamos ver o que alguns autores sobre o tema acreditam serem as características e valores que sustentam essa nova realidade social. O Quadro 3 apresenta uma comparação. 
Todos os autores falam em bens comuns, que é uma característica básica de qualquer comunidade, e de como seu uso deve (e pode) ser potencializado em prol de todos. Para Botsman e Rogers (2010), quando isso atinge uma massa crítica abre caminho para se transformar uma sociedade inteira. Um valor necessário para tudo isso é a confiança para se fazer compartilhamentos, trocas e locações entre estranhos. O papel de uma sociedade está na criação de confiança; reputação em uma comunidade digital facilita trocas e compartilhamentos.

Gansky (2010) acredita que compartilhamento é que define o propósito das redes sociais, seja local ou global; e se sustenta em tecnologias digitais; acontece com imediatismo (em qualquer hora e lugar); apoiada nos comentários dos usuários para difusão do conhecimento (o que vale a pena, ou não) e acontece em grande escala global. Com essa sofisticação no uso da informação o uso de ativos se torna mais eficiente, o que diminui a pressão por recursos naturais. Um efeito prático é que esse processo identifica melhor os ativos ociosos (ou com pouco uso) pelo uso eficiente das tecnologias e redes digitais, tornando-os visíveis e compartilháveis. Outro efeito seria que menos materiais e energia seriam necessários para produzir bens de consumo com a maior utilização dos ativos já disponíveis, eliminando desperdícios e otimizando recursos naturais, materiais e financeiros. O planeta agradece.

Quadro 3. Características e valores da Economia Colaborativa e Consumo Compartilhado

\begin{tabular}{lll}
\hline \multicolumn{1}{c}{ Autores } & & \multicolumn{1}{c}{ Características e Valores } \\
\hline Botsman e Rogers & $\checkmark$ & Massa crítica (escala) \\
& $\checkmark$ & Capacidade ociosa \\
& $\checkmark$ & Crença em bens comuns \\
& $\checkmark$ & Confiança em estranhos (reputação) \\
\hline Gansky & $\checkmark$ & Compartilhamento (por definição) \\
& $\checkmark$ & Rede digital avançada \\
& $\checkmark$ & Imediatismo (aqui e agora) \\
& $\checkmark$ & Escala global (potencial) \\
& $\checkmark$ & Valor (a troca cria valor) \\
Stephany & $\checkmark$ & Capacidade ociosa \\
& $\checkmark$ & Acesso online \\
& $\checkmark$ & Comunidade (confiança e interação social) \\
& $\checkmark$ & Baixa necessidade de propriedade (bens se tornam serviços) \\
\hline
\end{tabular}

Fonte: elaborado pelo autor, a partir dos textos de Botsman e Rogers, 2010; Gansky, 2010 e Stephany, 2015.

Em resumo, Stephany $(2015$, p.9) afirma que Economia Compartilhada cria valor pelo uso de ativos ociosos, tornando-os acessíveis para a comunidade através de tecnologias digitais, conduzindo as pessoas a uma baixa necessidade de posse desses mesmos ativos.

Para Botsman e Rogers (2010), o desenvolvimento da economia compartilhada deve-se a uma conjunção de fatores sociais, econômicos e tecnológicos:

- No que tange aos fatores sociais, constata-se uma crescente preocupação com questões relacionadas à sustentabilidade e meio-ambiente. $\mathrm{E}$ ao desejo dos participantes de fazerem novas conexões sociais.

- Quanto aos fatores econômicos, a economia compartilhada possibilita a monetização do excesso e da ociosidade dos estoques individuais. Também facilita empreendedorismo e a criação de valor na economia

- E, por fim, os fatores tecnológicos proporcionaram a disseminação de redes sociais e a redução dos custos das transações peer-to-peer, conectando diretamente consumidores a produtores e 
reduzindo os custos de intermediação.

A evolução das tecnologias de processamento, armazenamento e largura de banda móvel da Internet estimulou a expansão do empreendedorismo digital, no qual o baixo custo marginal tornou possível a oferta de novos produtos e serviços, bem como o desenvolvimento de novos modelos de negócio (ANDERSON, 2009). Esses sites aproveitaram os avanços tecnológicos que propiciaram redução dos custos das transações online para explorarem os mercados secundários (SCHOR, 2014). Isso permitiu a criação de um número cada vez maior de novas plataformas digitais de negócios que promoveram a expansão da Economia Compartilhada (GANSKY, 2010).

Quanto aos fatores econômicos, a Economia Compartilhada permite que as pessoas fiquem menos dependentes de empregadores e mais capazes de diversificar as suas fontes de renda, fazendo surgir um novo modelo econômico em que as pessoas ficam menos dependentes de empregadores e mais capazes de diversificar as suas fontes de renda (DUBOIS; SCHOR; CARFAGNA, 2014). O Consumo Compartilhado traz vantagens econômicas em formatos variados, pode se tornar uma fonte de renda alternativa através da locação de bens com capacidade ociosa, pela prestação de serviços diversos e até revenda de produtos.

A Economia Compartilhada é muito diversificada ao oferecer trocas, comércio, serviços e modelos de negócios, vai de uma estrutura de mercado, de um lado, até negócios sem fins lucrativos, de outro. Tal diversidade pode explicar sua popularidade e seu potencial de crescimento. $O$ curioso é que está criando um modelo de negócio que está a meio caminho entre capitalismo e socialismo, e em nenhum dos extremos, pois há uma intermediação direta entre as partes envolvidas.

De forma aberta, projetos colaborativos apelam para as necessidades individuais de seus participantes e também de sua autonomia, e ao mesmo tempo proporciona um senso de pertencer a algo maior, à uma comunidade. [...] "um novo e promissor mecanismo econômico e social que começa a equilibrar necessidades individuais e comunitárias com nosso planeta isso é que chamamos de Consumo Colaborativo". (BOTSMAN e ROGERS, 2010, p.63).

\section{Plataformas Digitais e Modelos de Negócios}

Villanova (2015) mostra em seu estudo uma classificação das plataformas digitais de modo organizado e ilustrativo, de acordo com as atividades que constituem e diferenciadas por meio da taxonomia proposta por Botsman e Rogers (2010). No Quadro 4 podemos ver uma categorização das atividades da Economia Compartilhada, que propõe a existência de três sistemas distintos: sistema de serviço e produto, mercado de redistribuição, e estilo de vida colaborativo.

A autora explica que o sistema de serviços de produtos caracteriza-se pelo uso de determinados ativos sem haver a necessidade de adquiri-lo, onde há o pagamento pelo uso de determinado bem ou produto durante um período de tempo. É compartilhamento de bens de propriedades de terceiros, seja de uma empresa ou de uma pessoa física, colocados à disposição de clientes e usuários das referidas plataformas digitais. O que move as pessoas nesse sistema de compartilhamento é a seguinte questão: preciso mesmo ter esse bem para satisfazer minhas necessidades? Se a resposta for não, então não é preciso possuir o bem de forma particular ou individual, e sim em uma base coletiva para uso somente quando necessitar, desembolsando dinheiro somente pelo uso ou acesso como ocorre com Uber (carros) BikeRio (bicicletas), BoBAGS (bolsas e acessórios) e Netflix (filmes e séries).

As plataformas de redistribuição caracterizam-se pela troca de produtos que já não tem utilidade para um indivíduo, permitindo sua reutilização por outras pessoas interessadas. A maioria das plataformas opera sem fins lucrativos, somente a base de troca, arte do escambo puro e simples, que é a realização de trocas de produtos sem o uso de moeda. Exemplos como Temaçucar, Tomaladacá e $X$ cambo atuam nessa linha. Mas existem algumas que realizam a venda por dinheiro como Ebay (EUA) e MercadoLivre (Brasil). Para Botsman e Rogers (2010), o lado interessante desse modelo de negócio é que ele faz a redistribuição de ativos para serem reutilizados e assim aumentar sua vida útil. E isso é uma forma sustentável de poupar recursos naturais: redistribuição é o quinto "R" - reduzir, reciclar, reusar, reparar e redistribuir - e é considerada uma forma sustentável de atividade econômica. 
Quadro 4. Plataformas digitais e modelos de negócios

\begin{tabular}{lll}
\hline Taxonomia & Exemplos de Atividade \\
\hline Sistemas de serviços de & $\checkmark$ Bike Rio (compartilhamento de bicicletas) \\
produtos & $\checkmark$ B-Cycle - EUA (compartilhamento de bicicletas) \\
& $\checkmark$ Zascar (compartilhamento de carros - B2P) \\
& $\checkmark$ Zipcar - EUA (compartilhamento de carros - B2P) \\
& $\checkmark$ RelayRides - EUA (compartilhamento de carros - P2P) \\
& $\checkmark$ Netflix (compartilhamento de filmes) \\
& $\checkmark$ Buscalá (aluguel de produtos diversos) \\
& $\checkmark$ & BoBAGS (locação de bolsas - B2P) \\
\hline Mercados de & $\checkmark$ & TemAçucar (empréstimos e doação entre vizinhos) \\
redistribuição & $\checkmark$ Tomalaca (troca de produtos e serviços) \\
& $\checkmark$ Xcambo (troca de produtos) \\
& $\checkmark$ Trocandolivros (troca de livros) \\
& $\checkmark$ Projeto Gaveta (clothing swap - troca de roupas) \\
& $\checkmark$ Trocacasa (troca de casas entre viajantes pelo mundo) \\
& $\checkmark$ BoxKids (troca de brinquedos) \\
\hline Estilo de vida colaborativo & $\checkmark$ & The Hub (Ambiente de trabalho compartilhado) \\
& $\checkmark$ Nós (Ambiente de trabalho compartilhado) \\
& $\checkmark$ Couchsurfing (compartilhamento de hospedagem gratuito) \\
& $\checkmark$ Airbnb (compartilhamento de hospedagem) \\
& $\checkmark$ Zimride EUA (sistema de caronas) \\
& $\checkmark$ Wegocaronas, Ponga.Mobi, Tripda (sistema de caronas) \\
& $\checkmark$ KickStarter (crowdfunding) \\
& $\checkmark$ Catarse ((crowdfunding) \\
& $\checkmark$ Wikipedia (crowdsourcing) \\
& $\checkmark$ Bliive (troca de serviço - banco de tempo) \\
& $\checkmark$ & Timerepublik (troca de serviço - banco de tempo) \\
\hline
\end{tabular}

Fonte: Adaptado de Villanova (2015, p. 24).

Já as plataformas de estilo de vida colaborativo caracterizam-se pela agremiação de pessoas com interesses comuns e que desejam compartilhar bens e serviços, bem como tempo disponível, ou habilidades e conhecimento, para executar tarefas. Não é só bens físicos e tangíveis como carros e bicicletas para compartilhamento, pessoas estão trocando tempo e habilidades (Bliive e TimeRepublik - atuam como banco de tempo), compartilhando espaço de trabalho (The Hub e Nós) e hospedagem (Airbnb) com interesse em trocar experiências e conhecimento, que são bens intangíveis e formam um estilo de vida.

\section{A Corporação Digital, Empreendedorismo e Mercado de Trabalho}

Isso tudo tem exigido algumas mudanças complementares no modo atual de organizar a atividade econômica. Um (re)desenho do modo de desenvolver atividades gerenciais. Inovação seria a palavra adequada para explicar a buscar atual por melhorias no desempenho empresarial.
O progresso na digitalização dos modelos de negócios conduz a um aumento no crescimento nos processos e na atividade econômica, por um lado expandindo os limites geográficos das empresas tradicionais, e por outro lado, levando à uma diminuição na expansão vertical: uma redução no tamanho e profundidade do organograma e hierarquias organizacionais. Uma ideia que faz sentido é aumentar a terceirização de muitas atividades e diminuir departamentalização (e hierarquias) nas organizações.

Motoristas do Uber são também microempreendedores que possuem seu próprio veículo e pagam sua manutenção enquanto constroem seu micro negócio no setor de serviços. Ao mesmo tempo, a corporação Uber sustenta que é apenas uma empresa de tecnologia que simplesmente proporciona uma plataforma que conecta usuários (clientes) da mesma maneira que Airbnb auxilia anfitriões a encontrarem viajantes, ou turistas, que 
necessitem de acomodações. (SUNDARARAJAN, 2016, p. 159). Mas podemos ver de outra maneira, a plataforma Uber coordena uma das maiores frotas de veículos do planeta para locação e transporte sem possuir nenhum deles, sem ter nenhum departamento comercial para tal finalidade, sem recrutamento e seleção para tantos funcionários, sem necessidade de oficinas para manutenção da frota, ou seja, é uma corporação bem enxuta. O mesmo ocorre com o Airbnb, que não possui nenhum quarto, casa, ou vila e oferece a maior quantidade de espaços para locação no planeta sem ter a posse de nenhum desses espaços, economizando em estrutura, organogramas e hierarquias em seu modelo de negócio. Percebemos que empreendedorismo e corporações digitais formam um novo modelo de negócio.

Outro fato interessante, percebemos atualmente o surgimento de um tipo muito específico de micro empreendedorismo em atividades inovadoras, que em vez de contratar uma equipe específica para os fins pretendidos pela empresa, prefere terceirizar publicamente (outsourcing) postando um conjunto de desafios ou requisições em determinada plataforma digital, deixando as melhores ideias virem à tona e capturando essas inovações trazendo-as para o processo produtivo. [...] É um paradigma lastreado em coletivos populares (crowd-based) chamado de "inovação aberta" (open innovation) - um conceito de que empresas podem e devem usar ideias externas na condução de suas atividades econômicas. (SUNDARARAJAN, 2016, p. 74-75).

Em seu livro, Sundararajan (2016) traz o exemplo da plataforma Threadless, que é descrita e apresentada em um Estudo de Caso da Harvard Business School (http://www.hbs.edu/faculty/Pages/item.aspx?n um=36152). Em resumo, é uma empresa produtora de camisetas no segmento fashion, localizada em Chicago (EUA), que não emprega ou contrata nenhum "estilista" para desenhar as coleções que são lançadas semanalmente. Os modelos e desenhos são $100 \%$ criados e escolhidos por uma comunidade de 500.000 colaboradores, sempre aberta a adesão de novos participantes. A empresa encoraja este coletivo online a participar enviando desenhos, modelos, comentários, postar músicas e vídeos inspirado pelos desenhos e escolher semanalmente a nova coleção.
Há outro exemplo de inovação aberta (open innovation), trata-se da Ideo que também é uma empresa de design, que fez a iniciativa de criar a plataforma Openldeo. Essa plataforma estimula um processo de inovação aberta para criar soluções para questões sociais e ambientais que afligem diversas localidades no mundo todo através de sua plataforma online (https://challenges.openideo.com/challenge).

Todas as iniciativas têm patrocinadores, o que eles buscam é a participação das comunidades envolvidas e de pessoas que tenham tempo e conhecimento para doar em prol das soluções desejadas. O grande desafio é esse: conectar as pessoas em busca de um bem comum.

E quando a terceirização de atividades ganha escala global? Offshoring refere-se a uma prática empresarial de usar uma força de trabalho que mora e vive em um país diferente daquele onde a empresa está localizada. Assim como as gerações anteriores testemunharam a mudança da economia agrícola para a economia industrial e depois dessa para economia de serviços, nós estamos agora em uma época onde pelo menos alguns tipos de trabalho não são mais definidos por localização. Esse movimento é direcionado por três fatores: o desenvolvimento de plataformas digitais que possibilitam às empresas recrutar e monitorar mão-de-obra pelo mundo todo, mudanças tecnológicas que capacitam trabalhadores a atender clientes em qualquer lugar, e a entrada de países densamente populosos (incluindo Índia e China) na economia global. (BLINDER, 2007).

Sundararajan (2016) fornece dois exemplos interessantes: as plataformas Management Consulting (EUA) e Universal Avenue (Suécia) disponibilizam equipes inteiras de vendedores para atuar em qualquer lugar, de acordo com a demanda, que pode ser integrada ao departamento comercial de qualquer empresa pelo tempo que for necessário. Trata-se de um tipo muito especial de terceirização: aquela que é feita utilizando mão-de-obra de outros países. Ou seja, uma empresa irá buscar trabalhadores capacitados onde quer que eles estejam, desde que o serviço a ser prestado possa ser entregue facilmente a longas distâncias. E é justamente isso que as TIC's fazem, conectam todos em qualquer lugar do planeta para comunicar e trocar arquivos, mensagens e informações que podem ser de uso econômico ou corporativo. Se há uma plataforma digital avançada, então qualquer atividade por complexa que seja pode 
ser subdividida em pequenas partes para que seja executada até por não-especialistas, em qualquer lugar conectado e online, seja no mundo físico, seja no mundo virtual.

Para Blinder (2007) o que é importante saber quando se fala de terceirização fora dos limites de uma região, ou país, é a distinção entre duas formas diferentes de classificação de serviço: serviço entregue pessoalmente (entregue em mãos) e serviço entregue de forma impessoal (via digital ou eletrônica, por exemplo): (01) A primeira categoria é oferecida localmente e permeia uma grande variedade de empregos, que vão de monitores de limpeza e babás, no lado dos salários baixos, até cirurgiões e diretores executivos, no lado dos salários altos; (02) a segunda categoria de serviços é oferecida a partir de qualquer localidade e inclui ambos os lados, tanto dos salários baixos e dos salários altos, a diferença está na entrega do serviço, que normalmente é entregue à longa distância, a exemplo de trabalhadores em uma empresa de "central de atendimento" ou "telemarketing" que atende clientes em qualquer lugar do país ou do planeta.

O que é importante focar e ter em mente é que não são as habilidades necessárias ou as credenciais educacionais requeridas ao emprego, e sim se o serviço em questão pode (ou não) ser entregue eletronicamente a longas distâncias sem comprometer a sua qualidade. Por exemplo, serviços como alimentação e hospedagem não são serviços "offshorable" ou exportáveis, pois são entregues pessoalmente. Ao contrário da sabedoria convencional, as ocupações (empregos) mais exportáveis não são aquelas de baixos ganhos, mensuradas por salários ou por educação. A correlação entre habilidades profissionais e offshorabilidade é quase zero. [...] nenhum nível de habilidade ou educação pode prevenir alguém do impacto da exportação de empregos (BLINDER, 2007, p. 3).

O trabalho está sendo subdividido em pequenas partes, micro partes, que cada um pode fazer e, em conjunto, entregar a tarefa toda pronta. Pequenas partes que não exigem especialização de forma geral, onde cada um pode dar sua contribuição para o projeto. Plataformas de Economia Compartilhada estão favorecendo um número crescente de nãoespecialistas a se tornarem provedores de serviços com nível de qualidade exigido pelo mercado de atuação, capacitados pela tecnologia e qualidade técnica disponibilizada pelas próprias plataformas digitais (SUNDARARAJAN, 2016). É um movimento econômico que faz (re)surgir o profissional generalista que entende de tudo um pouco, não sendo necessário ser especialista para montar seu negócio, isso é alcançado através de parcerias.

Nós estamos vendo um desmantelamento de locais de trabalhos centralizados ao passo que cada vez mais os negócios funcionam sem um local de trabalho fixo, ou escritório-sede, e sem uma equipe de trabalhadores designados permanentemente, optando por construir empresas desenhadas para operar com equipes contratadas exclusivamente para executar determinadas tarefas voltadas para projetos específicos. (SUNDARARAJAN, 2016). Cada projeto, uma equipe: fim do projeto, fim do contrato. As plataformas digitais se tornaram os novos locais de trabalho e de encontro entre os usuários e os provedores de serviços e produtos.

Novos mercados, sejam físicos ou virtuais, aumentam a facilidade de acesso a serviços e produtos que atendem a necessidade dos indivíduos, e de forma geral, acabam por gerar uma demanda por trabalho pois se torna mais factível para as pessoas encontrarem provedores daquilo que precisam.

De muitas maneiras, pode-se ver o surgimento da Economia Compartilhada como o ápice de um processo natural da tendência rumo à "corporação digital", à terceirização e à inovação aberta e sua permeabilidade dos limites das empresas. Pensando dessa maneira, os coletivos e comunidades se movem da posição de simples provedores de ideias (open innovation) para provedores atuais dos serviços (capitalismo das plataformas e comunidades coletivas). (SUNDARARAJAN, 2016, p. 77)

\section{DISCUSSÃO E CONSIDERAÇÕES FINAIS}

O movimento evolutivo na economia se dá ao longo do tempo com a construção de valores e crenças de nossa sociedade. É uma questão de comportamento coletivo com reflexos sobre os modos de vida e modelos de negócios, com reflexos sobre a atividade econômica em si. O movimento vem das pessoas e molda a sociedade e se torna um modo de vida que atinge a atividade econômica por meio das trocas, do comércio e dos serviços prestados. Quem sabe, uma mudança envolvendo compartilhamento e colaboração seja necessária para o mundo dos negócios. Pois afeta questões capitais envolvendo 
propriedade e consumo, alocação e distribuição de recursos naturais, materiais e financeiros.

As mudanças que discutimos nesse artigo estão ocorrendo em um tempo que ocorre uma extraordinária confluência entre tecnologias digitais e desenvolvimento cultural que torna a realização desses valores não somente possível, mas duradoura. Compartilhamento sempre dependeu de uma rede, e atualmente nós temos uma que está redefinindo seu propósito, significado e possibilidades: a Internet. De muitas maneiras, pode-se ver o surgimento da Economia Compartilhada como o ápice de um processo natural da tendência rumo à "corporação digital", à terceirização e à inovação aberta e sua permeabilidade dos limites das empresas. A Economia Colaborativa tem um amplo espectro: oferece trocas, comércio, serviços e diversos modelos de negócios, contempla desde corporações competindo globalmente até pequenas empresas sem fins lucrativos. Essa amplitude pode explicar sua popularidade e seu potencial de crescimento.

A evolução do consumo colaborativo é um fenômeno que traz uma mudança no comportamento social e formatará a atividade econômica, cada vez mais os novos mercados serão disponíveis e viabilizados através de plataformas digitais onde todos irão compartilhar, trocar vender ou comprar "excessos de capacidade e propriedade". A complexidade das mudanças indica uma evolução muito rápida no modo como a sociedade estabelece sua atividade econômica, o que explica em parte a dificuldade de vermos tudo com clareza, afinal, a mão-de-obra é local ou global? Plataformas digitais ou empresas? Comunidades ou colaboradores? Provedores de serviços ou emprego? Vamos nos acostumando: este será o caminho para as profissões do futuro, com um componente cada vez maior de trabalho autônomo e empreendedor, habilitado digitalmente, para se executar tarefas e projetos que serão cada vez mais colaborativos, com baixa necessidade de propriedade de ativos e extenso uso do consumo compartilhado, rumo a uma sociedade mais sustentável. Finalmente, o planeta agradece!

\section{REFERÊNCIAS}

ANDERSON, C. Free: o futuro dos preços. 6. ed. Rio de Janeiro: Elsevier, 2009.

BLINDER, A. How many US Jobs might be offshorable? CEPS, working paper no 142, Princeton, NJ, March, 2007.

Disponível em:

http://www.princeton.edu/ceps/workingpapers/ 142blinder.pdf. Acesso em: 16 jun, 2017.

BOTSMAN, R.; ROGERS, R. What's mine is yours: the rise of collaborative comsumption. New York, NY, HarperCollins Publishers, 2010.

DUBOIS, E.; SCHOR, J.; CARFAGNA, L. Connected Consumption: A sharing economy takes hold. Rotman Management Spring, p. 50-57, 2014.

GANSKY, L. The Mesh: why the future of business is sharing. New York: Portfolio Penguin, 2010. Disponível em:

http://informationdj.files.wordpress.com/2012/0 $1 /$ future-of-business-is-lisa-gansky.pdf. Acesso em: 16 jun, 2017.

STEPHANY, A. The business of sharing: making it in new sharing economy. London: Palgrave MacMillan, 2015.

https://doi.org/10.1057/9781137376183

SCHOR, J. Debating the sharing economy. Great Transition Iniciative, 2014. Disponível em: http://greattransition.org/publication/debatingthe-sharing-economy. Acesso em: 14 jun. 2017. https://doi.org/10.1093/oxfordhb/978019069558 3.013 .32

SUNDARARAJAN, A. The sharing economy: the end of employment and the rise of crowd-based capitalism. Cambridge, MA: The MIT Press, 2016.

SUROWECKI, J. Uber Alles, New Yorker, p. 2, sept. 16, 2013.

http://newyorker.com/magazine/2013/09/16/ub er-alles-2. Acesso em: 14 jun, 2017.

VILLANOVA, Ana Luisa Ilha. Modelos de negócio na economia compartilhada: uma investigação multi-caso. 125 f. Dissertação (Mestrado em Administração) - Escola Brasileira de Administração Pública e de Empresas, 2015. 